\title{
Imprensa e políticas de saúde pública: a contribuição dos jornais na legitimação do isolamento compulsório dos leprosos em Minas Gerais (1930)
}

\author{
Keila Auxiliadora Carvalho ${ }^{1}$ \\ Ramon Feliphe Souza ${ }^{2}$
}

Resumo: O objetivo do presente texto consiste em analisar matérias e anúncios que tratam do combate à lepra, publicadas nos jornais, Estado de Minas e Minas Gerais, no início dos anos de 1930, marco inicial da estruturação da política de isolamento compulsório dos doentes no estado. Para além de mapear o aparecimento de notícias relacionadas ao tema, pretendemos compreender a dimensão do uso dos jornais como veículos difusores e legitimadores de políticas públicas de saúde. A questão da legitimidade pública, nesse caso, torna-se importante, pelo fato de a principal prática de controle da lepra consistir no isolamento obrigatório dos portadores da doença.

Palavras-Chave: imprensa, saúde pública, lepra; história; Minas Gerais

Abstract: The aim of this paper is to analyze stories about the results of leprosy treatment, published on newspapers Estado de Minas and e Minas Gerais, beginning of the 1930s, the initial framework for the structuring of the compulsory isolation policy for patients. In addition to mapping the news related to the theme, we intend to understand the use of this newspapers as vehicles for diffusing and legitimating of public health policies. The question of public legitimacy, in this case, becomes important because the main practice of leprosy control consisted in the obligatory isolation of the people affected by the disease.

Keywords: Press, healthcare; leprosy; history; Minas Gerais

1 Doutora em História Social. Professora Adjunta da Universidade Federal dos Vales do Jequitinhonha e Mucuri - UFVJM. E-mail: <keilaacarvalho@gmail.com>.

2 Doutorando em História das Ciências e da Saúde pela Casa de Oswaldo Cruz - Fiocruz. 


\section{Introdução}

A década de 1930 foi o auge da política isolacionista,a partir da consolidação do modelo tripé: dispensário, leprosário, preventório. Por este modelo, várias instituições foram erguidas nos quatro cantos do país. Em Minas Gerais, espaço no qual foi desenvolvida a pesquisa que deu origem ao presente texto, a ofensiva contra a doença fora inaugurada junto com a Colônia Santa Izabel, em 1931. A cada nova instituição que se inaugurava no estado, os leprólogos conclamavam a população a contribuir na campanha, fosse denunciando casos novos ou auxiliando as "Sociedades de Proteção aos Lázaros". No ano de 1945, por exemplo, já haviam sido instalados seis grandes leprosários em Minas Gerais, além de dispensários e preventórios, uma verdadeira rede de instituições destinadas a isolar leprosos, controlar os novos casos e cuidar dos filhos dos doentes.

O objetivo deste texto consiste em analisar matérias e anúncios que tratam do combate à lepra, publicadas nos jornais, Estado de Minas e Minas Gerais, no início dos anos de 1930, marco inicial da estruturação da política de isolamento compulsório dos doentes no estado. Além de mapear o aparecimento de notícias relacionadas ao tema, pretendemos compreender a dimensão do uso dos jornais como veículos difusores e legitimadores de políticas públicas de saúde. A questão da legitimidade, nesse caso, torna-se importante, pelo fato de a principal prática de controle da lepra consistir no isolamento obrigatório dos portadores da doença. E, para isso, a mobilização da opinião pública era fundamental.

\section{Isolar, vigiar, orfanar}

Com o objetivo de romper com a apatia, em relação à incidência da lepra no Brasil, em 1922, foi realizada, no Rio de Janeiro, a "Primeira Conferência Pan-americana de Lepra”. Neste evento, que contou com representantes de vários países do continente, foram deliberadas as primeiras iniciativas, com o intuito de controlar a endemia de lepra na região. No relatório de conclusão da conferência, os leprólogos decidiram que, a partir daquela data, reunir-se-iam a 
cada quatro anos, a fim "de promover o desenvolvimento progressivo dos estudos sobre a lepra e das medidas de higiene pública destinadas a combatê-la" (Conclusões...,1946, p. 195). A preocupação com a doença se intensificava, bem como o apelo para que os governos investissem na organização de uma estrutura de saúde pública destinada ao controle da mesma.

\begin{abstract}
A Primeira Conferência Americana de Lepra, zelando pelos mais relevantes interesses sanitários e atuando de acordo com os altos ideais da humanidade, resolve levar aos países que nela se fizeram representar, a indicação premente da urgência com que deverão ser praticadas medidas sanitárias, que atendam a magnitude do problema da lepra; resolve ainda fazer um chamado aos Governos daqueles países, no sentido de que organizem, sobre bases adiantadas e eficientes, a assistência médico-social dos leprosos. (Conclusões...,1946, p. 195)
\end{abstract}

A mobilização em torno deste tema se devia, em parte, à perspectiva saneadora, tanto do Brasil, quanto dos demais países da América Latina, já que, naquele momento, as sociedades latino-americanas enfrentavam dilemas cruciais, tais como: a delimitação do papel do Estado na promoção do bem-estar da população e, sobretudo, a necessidade de se inserirem no mundo moderno e civilizado. Conscientes destas questões, os sanitaristas se utilizavam do discurso "reformador" da sociedade para colocarem as suas demandas na pauta do poder público. Um forte argumento utilizado por eles foi a possibilidade de os países latino-americanos se tornarem reconhecidos como nações "leprosas".

Sendo assim, diante da premência em tratar o problema, outra conclusão importante da Conferência foi relativa ao modelo de organização a ser adotado no controle da doença.

\begin{abstract}
Em cada país o combate contra a lepra deverá ser orientado sobre um plano uniforme, cuja aplicação será extensiva a quaisquer regiões, nele sendo interessados os departamentos administrativos. Será de toda conveniência que o Governo nacional centralize, tanto quanto possível, as providências administrativas e oriente os Estados, Províncias ou Departamentos, na Campanha contra a lepra, e principalmente nas medidas técnicas essenciais. (Conclusões...,1946, p.196-197)
\end{abstract}

A intenção era envolver totalmente os governos no processo de combate à lepra, adotando um padrão centralizador. Tal orientação possuía impli- 
cações profundas no Brasil, uma vez que, graças ao pacto federativo, os estados possuíam autonomia para deliberar sobre algumas questões, dentre as quais, sobre aquelas relativas à saúde, sem se submeterem ao governo federal. Os leprólogos brasileiros dispensaram, então, grandes esforços, a fim de que as orientações dessa "Primeira Conferência Pan-americana de Lepra" fossem rigorosamente seguidas. A estratégia adotada por eles consistiu em descrever a lepra como um problema nacional, portanto, passível de ser resolvido através da união de todos os estados da federação e, obviamente, da submissão destes às orientações do governo central. De acordo com Dilma Costa, "materializar o problema da lepra no Brasil significava conferir-lhe visibilidade para além do discurso médico, o que deu diferentes nuanças à trajetória da doença em se estabelecer como uma 'endemia nacional"' (COSTA, 2007, p. 245). Uma forma importante de materializar o problema era através da realização de censos, por isto, esta foi uma das mais incisivas orientações da conferência de 1922, a qual concluiu que "o ponto de partida indispensável para a organização de qualquer campanha contra a lepra é o respectivo censo, realizado com a maior amplitude e segurança possíveis" (Conclusões...,1946, p. 196). Isto, porque estes censos identificariam estatisticamente o número de leprosos e, consequentemente, criariam condições de convencimento sobre a urgência em solucionar a questão.

As estatísticas colocavam o Brasil entre os países com maior incidência de lepra no mundo. Nesse sentido, controlar esta doença passou a ser considerada uma etapa necessária ao processo de construção de nossa nacionalidade, base do projeto de civilizar e modernizar a nação. Dilma Costa observa que, dentre as estratégias utilizadas pelos leprólogos, estava a de "produzir um discurso em que, tal como nas endemias rurais, uma maior incidência da lepra seria creditada à ausência do Estado e à total omissão do poder público na formulação de políticas para seu controle" (COSTA, 2007, p. 245). Esta estratégia pode ser observada na fala do médico Olyntho Orsini, pois, em sua acepção,

O problema da lepra no Brasil esteve durante séculos ao abandono. Os governos, com raríssimas e honrosíssimas exceções, sempre preocupados com a lepra da política, esqueciam-se da lepra hanseniana, que tranquilamente estendia, pouco a pouco, a sua atividade a todos os recantos do país (ORSINI, 1935, p. 3). 
Através deste discurso, ao mesmo tempo em que se responsabilizava o Estado pela grande incidência da lepra, também era possível demandar dele ações efetivas para o seu combate. Tal empreitada significou construir possibilidades de negociação dos leprólogos com os governos, de forma a efetivar as políticas de controle da doença. Deste modo, "a ideia de que a lepra era uma doença que exigia medidas singulares de controle, partilhada por médicos e autoridades sanitárias, acabaria por constar no texto do decreto $\mathrm{n}^{\mathrm{O}}$ 13.538, que reorganizou o Serviço de Profilaxia Rural” [1]. Este decreto estabelecia que o serviço contra a enfermidade estivesse sujeito a um regime especial, que significava a construção de colônias de isolamento. Portanto, é possível afirmar que, através de um processo construído social e culturalmente, a lepra acabou por assumir o status de endemia nacional, em meio à preocupação sanitária - que marcou os anos de 1920 - com as doenças do mundo rural.

A partir deste primeiro momento, que envolveu a delimitação do problema representado pela lepra, teve início um movimento de controle da doença, que foi sefortalecendo continuamente, à medida que os leprólogos tentavam dar concretude aos argumentos do risco social e econômico que a enfermidade representava para a nação brasileira. O médico Olyntho Orsini resumiu o problema da seguinte forma: "o Brasil é verdadeiramente um grande foco de lepra, flagelo que o acompanha desde quase o seu descobrimento" (ORSINI, 1935, p. 3). Pode-se considerar, então, que a criação da Inspetoria de Profilaxia da Lepra e Doenças Venéreas [2], em 1920, foi uma das primeiras respostas do poder público ao discurso médico relacionado à lepra. As principais ações da Inspetoria procuraram instituir a obrigatoriedade da notificação da doença, o exame periódico nos comunicantes e o isolamento do leproso, nosocomial ou domiciliar. Neste momento, não havia ainda um plano estruturado de controle da doença, embora, seguindo as tendências dos congressos nacionais e internacionais, os leprólogos brasileiros tenham implantado estas primeiras práticas.

$\mathrm{O}$ isolamento viria a setornar a principal medida de combate à doença posteriormente, sobretudo a partir do Decreto Federal $n^{0} 16.300$, de 31 de dezembro de 1923, que reforçou a disposição de que o isolamento deveria ocorrer e, preferencialmente, em colônias definidas nesta norma, como estabelecimentos nosocomiais, ou seja, ambientes hospitalares. Mas, para que tal decreto fosse 
colocado em prática, foi preciso, antes, convencer os governos a investirem na construção das instituições para segregar os leprosos. Uma vez que, para além da urgência que se desejava imprimir ao problema da lepra, muitas eram as questões que se contrapunham à implementação de uma política isolacionista ao longo da década de 1920. Podemos citar como as duas principais: o pacto federativo de autonomia dos estados, que restringia a intervenção da União; e os problemas econômicos decorrentes de uma crise mundial.

Mas a Revolução de 1930 mudaria este panorama, sobretudo, a partir da posse de Gustavo Capanema no Ministério da Educação e Saúde Pública, em 1934. O processo de centralização política, promovido por Getúlio Vargas, atingiu também o campo da saúde. Para o caso específico do combate à lepra, as medidas profiláticas para combatê-la foram estruturadas em todo o país, a partir da união de três instituições: os asilos-colônias para isolar os leprosos, os dispensários para diagnosticar os comunicantes, e os preventórios para orfanar os filhos indenes dos doentes. Nesse sentido, esta estrutura foi denominada modelo tripé [3]. De acordo com os médicos leprologistas Orestes Diniz e José Mariano,

um organismo sanitário de luta contra a lepra, tecnicamente organizado, se assenta no tripé representado pelo Dispensário que procura, descobre e classifica o doente, no Leprocômio, que o isola, mantém e trata, e no Preventório que recolhe, observa e educa seus filhos ainda indenes da infecção (DINIZ \& MARIANO, 1945, p.103).

Estas três instituições, dispensário, leprosário e preventório, conforme observa Luciano Curi (2001, p. 112), pretendiam corresponder aos princípios básicos de: "isolar, vigiar e orfanar". A tarefa de "orfanar" os filhos dos leprosos, embora contasse com apoio do Estado [4], havia ficado a cargo da iniciativa privada. Mas por que estas crianças deveriam ser orfanadas? Porque, ao serem isolados nas colônias, os indivíduos doentes perdiam o contato com o mundo exterior, inclusive com os seus filhos, já que os leprosos representavam um perigo para os "sadios", ainda que se tratasse de seus próprios filhos. Uma vez dentro do leprosário, os internos poderiam cultivar novos laços, inclusive se casarem novamente. Mas casados, os doentes acabavam tendo filhos e, nesse caso, também não lhes era permitido educá-los. 


\section{Imprensa, Poder Público e Combate à Lepra em Minas Gerais}

Figura 1: Jornal Estado de Minas

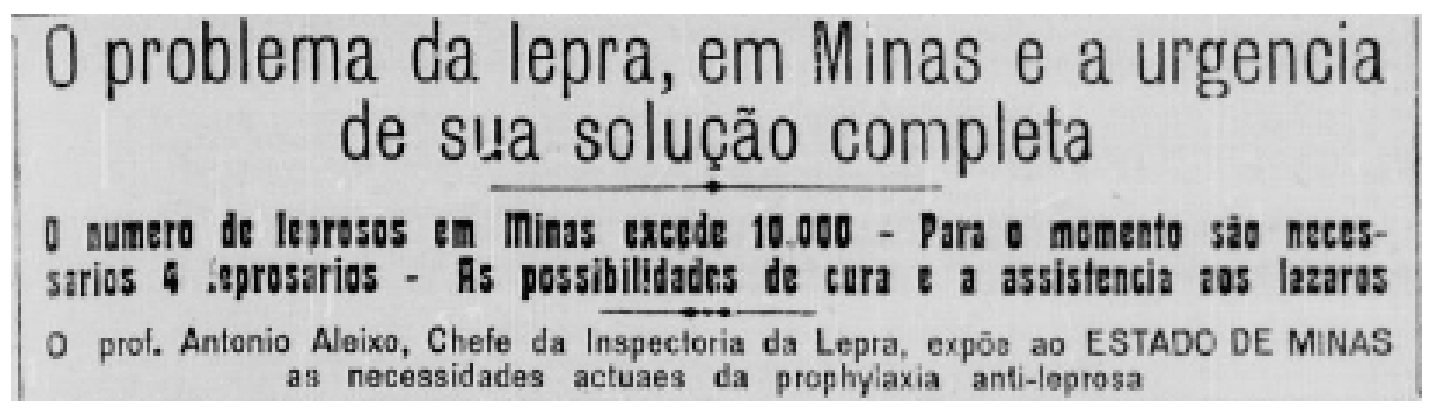

Fonte: Estado de Minas, 29 de janeiro de 1931, p.1.

A manchete apresentada acima ocupou a primeira página da edição de 29 de janeiro de 1931 do Estado de Minas. A longa entrevista do médico Antônio Aleixo, que ocupava o cargo de chefe da Inspetoria da Lepra no estado, tinha, por objetivo, expor as "necessidades da política anti lepra" em Minas Gerais. A base de argumentação do médico se sustentava no número de casos da doença. Por isso, a matéria destacava que "o número de leprosos em Minas excede 10.000", havendo, pois, necessidade de se construir, pelo menos, quatro leprosários no estado.

\footnotetext{
No intuito de esclarecer o assumpto devidamente, o Estado de Minas entrevistou o Dr. Antonio Aleixo, que, sobre ser uma reconhecida autoridade nesse assumpto, chefia a Inspectoria de lepra. A sua exposição, minuciosa, esclarece sufficientemente o assumpto, impondo-o á consideração do governo do Estado (ESTADO DE MINAS, 1931, p.1).
}

A clareza com que o Estado de Minas expõe os objetivos da matéria aponta uma questão importante para a discussão deste texto, qual seja: o papel da imprensa na legitimação da política de isolamento compulsório dos leprosos. Tal legitimidade carecia, em primeiro lugar, de ser dada pelo poder público, uma vez que o financiamento de uma política de profilaxia da lepra, baseada no modelo tripé, era extremamente dispendiosa. Assim, ao mesmo tempo em que o chefe da Inspetoria da Lepra expõe os problemas à sociedade, através da imprensa, também deixa claro que cabe ao poder público mineiro investir na superação desse quadro. Os argumentos sobre os quais se baseava a necessidade de investimento na área se davam a partir de densa exposição dos problemas causados pela lepra.Além disso, 
era apontada a solução "mais eficaz" para tal questão, sendo ela o isolamentodo doente. Conforme Antônio Aleixo, "o isolamento rigoroso de todos os leprosos contagiantes eis, infelizmente, por enquanto, o único recurso verdadeiramente efficaz para extinguir o flagelo da lepra" (ESTADO DE MINAS, 1931, p.1).

A retórica dos médicos, envolvidos com o combate da doença, enfatizava a premência em se conter a expansão da lepra, através do isolamento dos doentes. No caso de Minas Gerais, Antônio Aleixo destacava que, embora houvesse "técnicos", faltava investimento em infraestrutura,

recentemente, foi publicado um aviso official declarando ser inútil encaminhar doentes leprosos para o Centro de Saude, porque não havia recursos com que atendende-los. Era uma confissão tacita de que o Estado não se acha apparelhado nem ao menos para soccorrer os casos que surgem aqui na Capital, e que são uma evidente minoria (ESTADO DE MINAS, 1931. p.1).

Assim, na perspectiva do médico, embora estivesse em curso, desde 1926, a construção de uma grande instituição de isolamento em Minas Gerais, a Colônia Santa Izabel, seria necessário construir mais três leprosários regionais, em pontos estratégicos do estado, "facilitando o acesso e a própria assistência médica, familiar e social dos lazaros" (ESTADO DE MINAS, 1931, p.1).

Figura 2: Jornal Estado de Minas

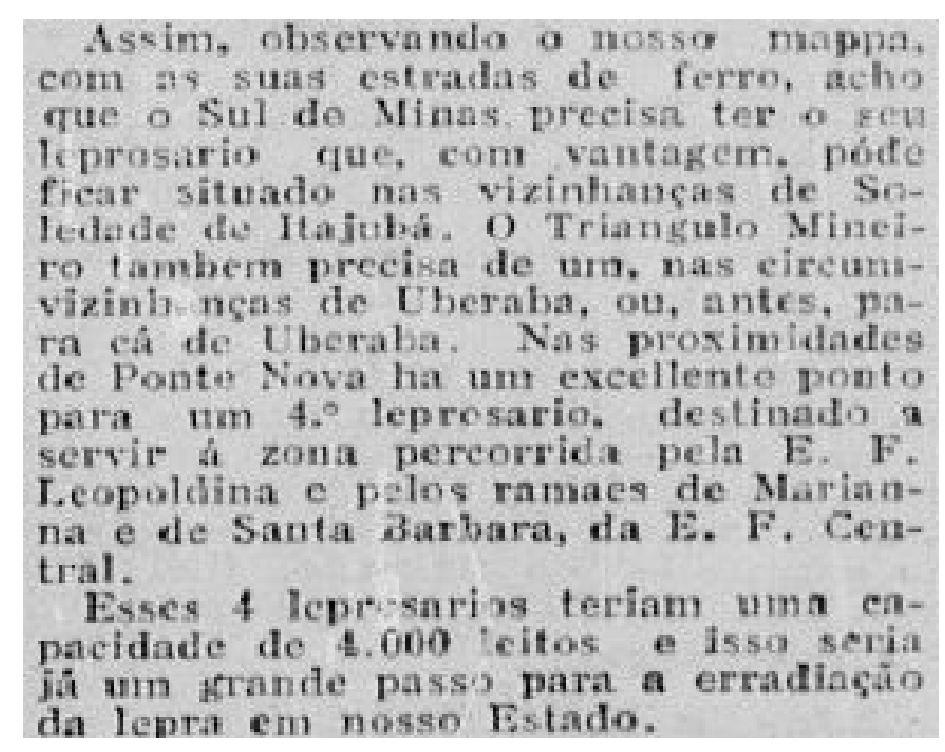

Fonte: Estado de Minas, 29 de janeiro de 1931, p.1. 
Menos de um ano após esta entrevista do chefe da Inspetoria de Lepra, as obras da Colônia Santa Izabel, em dezembro de 1931, foram concluídas.Contando com a presença de diversas autoridades - Dr. Olegário Maciel Dias, presidente do Estado, Dr. Noraldino Lima, Secretário de Educação e Saúde Pública e Dr. Ernani Agrícola, Diretor de Saúde Pública -, a instituição foi solenemente inaugurada, constituindo-se, pois, como um marco fundador da campanha contra a lepra em Minas Gerais. Os jornais Estado de Minas e Minas Gerais fizeram a cobertura do evento, publicando, com destaque, a notícia. Na ocasião, diversos discursos foram proferidos e todos apontavam para a ótica de que aquele também era o momento de "inauguração" de uma campanha profilática mais efetiva no Estado. O médico Antônio Aleixo, que seria o primeiro diretor da instituição, afirmava que a solenidade inaugural da Colônia Santa Izabel se constituía como "um momento de especial significação e de notável repercussão", pois refletia os métodos científicos de governar Minas Gerais, já que, graças à iniciativa do governo e seus auxiliares, os quais se empenharam infatigáveis nas providências necessárias para a conclusão das obras daquela Colônia, novos horizontes se abririam para a profilaxia da lepra, sendo este o "começo da redenção dos lázaros” (ESTADO DE MINAS, 1931b, p.1). O presidente do Estado, Olegário Maciel, mostrando-se grato pelos elogios à iniciativa de investimento na obra que ora inauguravam, afirmava que combater a lepra significava "proteger o Estado da degradação" (ESTADO DE MINAS, 1931b, p.1.).

Figura 3: Jornal Estado de Minas

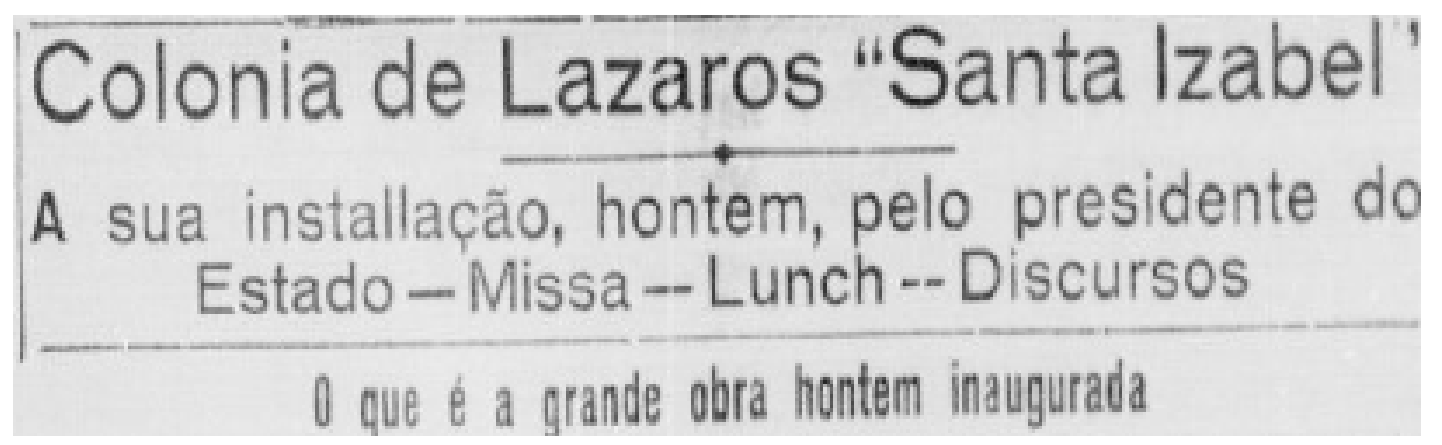

Fonte: Estado de Minas, 24 de dezembro de 1931, p.1. 


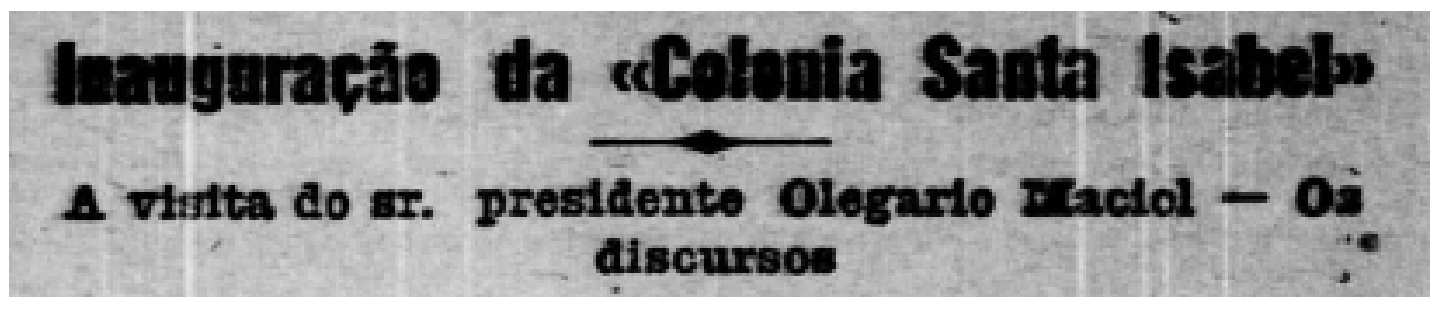

Fonte: Minas Gerais, 24 de dezembro de 1931, p.10.

Pela mudança na retórica de Antônio Aleixo, é possível compreender que a legitimação da política fora alcançada por parte do poder público. De fato, o combate à lepra ganhou espaço na agenda da saúde pública e, em outubro de 1937, foi sancionada a Lei ${ }^{\circ}{ }_{20}^{209}$, que instituiu o Serviço de Defesa Contra a Lepra, órgão destinado a orientar e dirigir a campanha contra a doença em Minas Gerais. O Serviço era formado de dois Departamentos, subordinados à Saúde Pública do Estado: o Centro de Estudos e o Serviço de Profilaxia, ambos com atribuições distintas, que lhes foram instituídas pela referida lei.

O Centro de Estudo de Lepra tinha, a seu cargo, a investigação científica da moléstia e dos processos de prevenção e cura. Assim, o Centro de Estudo era o Departamento responsável pelas pesquisas no campo da leprologia. E, a fim de preparar um corpo especializado de médicos leprologistas e auxiliares de laboratórios para atuarem neste campo, foi criado um curso de lepra, que se realizava periodicamente na Universidade de Minas Gerais, em cooperação com o Centro de Estudo de Lepra. O curso de leprologia da UMG recebia discentes de todas as regiões do país. Os professores do curso eram leprólogos conceituados, tanto da região, quanto de outros estados. Tal investimento, no campo da pesquisa, fez com que Minas se destacasse, realizando inúmeros estudos sobre a doença e sua etiologia.

O segundo Departamento subordinado ao Serviço de Defesa Contra a Lepra era o Serviço de Profilaxia, responsável pelas ações de combate à doença em Minas Gerais. Etse Serviço de Profilaxia era constituído pelos seguintes órgãos técnicos: seção administrativa; seção técnica; dispensário central de Belo Horizonte; dispensários regionais e serviços itinerantes; colônias agrícolas já existentes ou que foram criadas nas zonas de mais ocorrência da lepra; hospitais, sanatórios e asilos; preventórios. A instalação desses órgãos foi realizada, de 
acordo com a demanda de cada região, tendo em vista que, para fins profiláticos, o estado foi divido em 14 zonas. As zonas passaram a compor 04 microrregiões e, em cada uma destas, seria instalado um leprosário. Observemos, a seguir, o mapa que indica esta divisão.

Figura 4: Mapa com a divisão do Estado em zonas

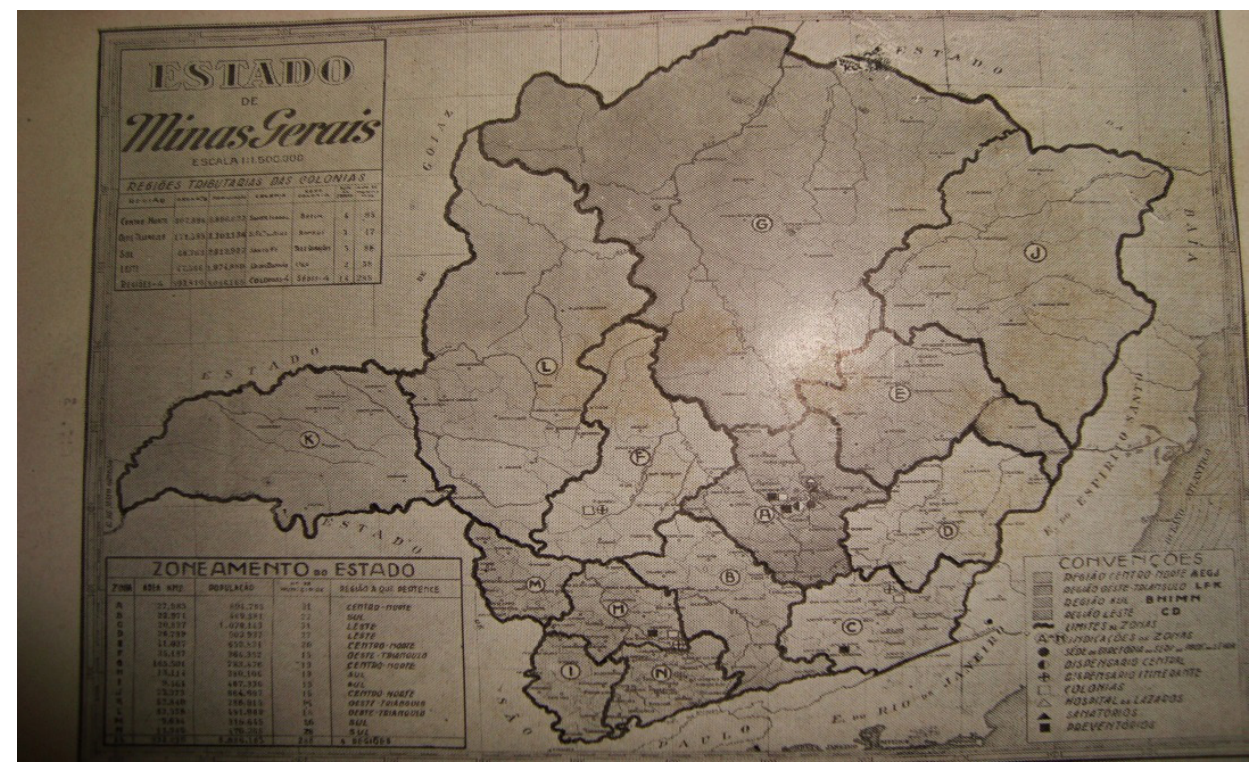

Fonte: Serviço de Lepra de Minas Gerais

Conforme se observa no mapa, as quatro microrregiões eram formadas da seguinte maneira: primeira (zonas A, E, J, G); segunda (zonas B, C, D); terceira (zonas F, L, K); e quarta (zonas H, I, M, N). A construção de uma instituição de isolamento - e seus correlatos, dispensário e preventório - em cada uma dessas regiões, tinha por objetivo promover o recolhimento dos leprosos de todas as regiões do estado.

Sobre esse conjunto de iniciativas do poder público, em relação ao combate à lepra, a edição do jornal Minas Gerais, de 04 de abril de 1937, trazia uma enorme reportagem, intitulada: "As Atividades do Governo Benedito Valadares" [5].Dentre as realizações do referido governador, estavam aquelas que se referiam à Saúde Pública, tendo como destaque as ações no campo da lepra. De acordo com a reportagem, graças à atenção dada à profilaxia da doença, "o estado dispõe hoje de uma excelente organização já em funcionamento” (MINAS GERAIS, 1937, p.7). Esta organização compreendia, além das instituições citadas anteriormente, 
A construção de mais um leprosário, a Colônia São Francisco de Assis, no município de Bambuí, com lotação inicial para 900 doentes.

Em Sabará está sendo concluído um Pavilhão destinado a detentos e psicopatas leprosos.

No corrente ano, o orçamento estadual consigna verba para a criação de quatro Dispensários que são localizados em diferentes pontos do Estado.

[...] com (o orçamento) que o Governo Federal acaba de destinar ao Serviço de Lepra do Estado, serão construídas mais duas Colônias regionaes, uma no Sul de Minas e outra na zona da Mata, já tendo sido adquirido para a primeira, o necessário terreno em Três Corações (MINAS GERAIS, 1937, p.7-8).

Como se pode observar, de fato, houve um intenso investimento do poder público na montagem de uma estrutura de combate à lepra. É preciso destacar que tais investimentos não foram realizados apenas no âmbito estadual. Como já salientado, a instauração de uma nova ordem política no Brasil, com a Revolução de 30, e, destacadamente, com a nomeação de Gustavo Capanema para o Ministério da Educação e Saúde em 1934, refletiu em mudanças no campo da saúde. Tais mudanças foram determinantes para as políticas de combate à lepra, que passaram a receber investimentos significativos do governo federal. Conforme destacou Laurinda Maciel (2007, p. 90), "foram firmados convênios com os Estados para repasse de verbas a serem utilizadas na construção ou reforma de leprosários”.

A lepra ganhou uma rede específica para o seu combate, tornando-se alvo dos profissionais que compunham a tríade institucional - Dispensário, Leprosário, Preventório. Tal contexto, segundo Luciano Curi (2002, p. 192), configurou uma "monopolização dos cuidados da lepra". Ainda de acordo com este historiador, a rede institucional hospitalar-assistencialista, montada no Brasil devido à lepra, com seu caráter especializado e inteiramente dedicado aos cuidados da doença, "tinha sua sobrevivência diretamente atrelada à manutenção da prática isolacionista e indiretamente do quadro endêmico nacional, uma autêntica "indústria da lepra"” (2002, p.196). Eram milhares de pessoas envolvidas no processo: profissionais da área de saúde, portadores da doença e filantropos.Ou seja, havia uma estrutura dinâmica, cujo desmantelamento não agradava a muitos.

A montagem de uma estrutura desta natureza não seria possível, sem a legitimação, tanto pelo poder público, quanto pela sociedade, do elemento chave 
do modelo tripé, qual seja: o isolamento compulsório dos doentes. Tal legitimidade vai sendo alcançada, a partir da difusão dos ideais isolacionistas, naturalizando a sua efetivação, sob a alegação de que era necessário para o "bem comum". Ou seja, isolar o portador de lepra passou a significar proteger os "sadios". Nesse sentindo, concomitante à montagem das políticas públicas de saúde, vão sendo aprimoradas ações filantrópicas para contribuir com a "luta" contra a lepra, que se concentravam, principalmente, na "Federação das Sociedades de Assistência aos Lázaros e Defesa Contra a Lepra (FSAL e DCL)" [6], com sede em vários estados, incluindo Minas Gerais. O historiador Luciano Curi, esclarece que:

\begin{abstract}
As atividades desta sociedade eram diversificadas, sendo: coleta de bem materiais para serem doados aos leprosos, confecção e publicação de panfletos explicativos e outros impressos que veiculavam conselhos médicos e esclarecimentos acerca da lepra, realização de festas e outros eventos cuja renda era revertida em prol das obras assistenciais e do custeio das despesas da entidade, denúncia da gravidade do problema da lepra através de artigos de jornais, conferências em rádio, debates e outras atividades dedicadas à "Formação da Consciência Nacional", até a colaboração com o governo, no caso paulista, na construção da rede de asilos-colônias que na época encontrava-se em fase de implementação (CURI, 2001, p.96).
\end{abstract}

A atuação das "Sociedades de Assistência" se mostrava efetiva na criação e manutenção dos Preventórios. Como já destacamos, estas instituições eram responsáveis por "orfanar" os filhos indenes de indivíduos isolados, em função da lepra. Assim, as iniciativas da referida entidade não estavam restritas aos aspectos materiais, uma vez que havia também uma preocupação em divulgar esclarecimentos sobre a lepra, a fim de promover uma conscientização na sociedade acerca dos "perigos da doença". Obviamente,a arrecadação de donativos para contribuir na campanha era a principal meta da entidade, mas, para que as pessoas pudessem doar, era necessário "acreditar" na causa. A crença na causa significava dar legitimidade à estrutura criada para combatê-la, sendo ela omodelo tripé. Os canais utilizados pelas "Sociedades de Assistência", para divulgar a necessidade de combater a lepra, variavam de acordo com o estado. Em São Paulo [7], por exemplo, criou-se o "Boletim mensal da SAL e DCL/SP", o qual alcançou grande sucesso de vendas e publicidade. 


\section{Imprensa, Sociedade e Combate à Lepra em Minas Gerais}

Em Minas Gerais, foram criadas sucursais da "Sociedade Mineira de Proteção aos Lázaros e Defesa contra a Lepra”, em diversas cidades. A entidade contava com espaço de divulgação na imprensa da capital, Belo Horizonte. Em pesquisa realizada no jornal Minas Gerais, por exemplo, constatamos que havia um espaço reservado para que a "Sociedade Mineira" divulgasse o seu trabalho, realizando a "conscientização" da população e clamando por ajuda. Apelava-se para o espírito "altruísta” do povo mineiro, para contribuir na luta contra a doença, sobretudo, através de doações. Nesse sentido, no mês de dezembro, quando se aproximava o Natal, eram publicadas notas das diversas sociedades espalhadas pelo estado, diariamente.

Selecionamos o mês de dezembro de 1931 para acompanharmos, no Minas Gerais, as notas da "Sociedade Mineira de Proteção aos Lázaros e Defesa contra a Lepra”. O referido ano foi escolhido, por tratar-se de um marco temporal na intensificação da campanha contra a lepra no estado. Como destacamos, ao longo do texto, no início de 1931, o governo do estado era advertido a tomar providências quanto ao avanço da doença. Segundo o chefe da Inspetoria da Lepra, Antônio Aleixo, Minas Gerais estava atrasada em relação à profilaxia da lepra. Em 24 de dezembro do mesmo ano, o médico voltava a falar sobre o tema, mas, desta vez, com perspectiva positiva, considerando a inauguração da Colônia Santa Izabel como marco do avanço nesta área.

A edição do dia 03 de dezembro destinou 1/4 de página para assuntos relativos à "Sociedade Mineira de Proteção aos Lázaros e Defesa contra a Lepra”. Neste espaço, fora divulgada a criação de uma filial da entidade em Nova Lima, cidade próxima à capital mineira. Além disso, divulgou-se nota sobre uma solicitação do Rotary Club para que as prefeituras dos municípios mineiros contribuíssem com uma quantia anual destinada a auxiliar a "Sociedade Mineira...". Ao apelo, mais de 70 municípios já haviam respondido positivamente, conforme elencado no trecho abaixo: 
Figura 5: Jornal Estado de Minas

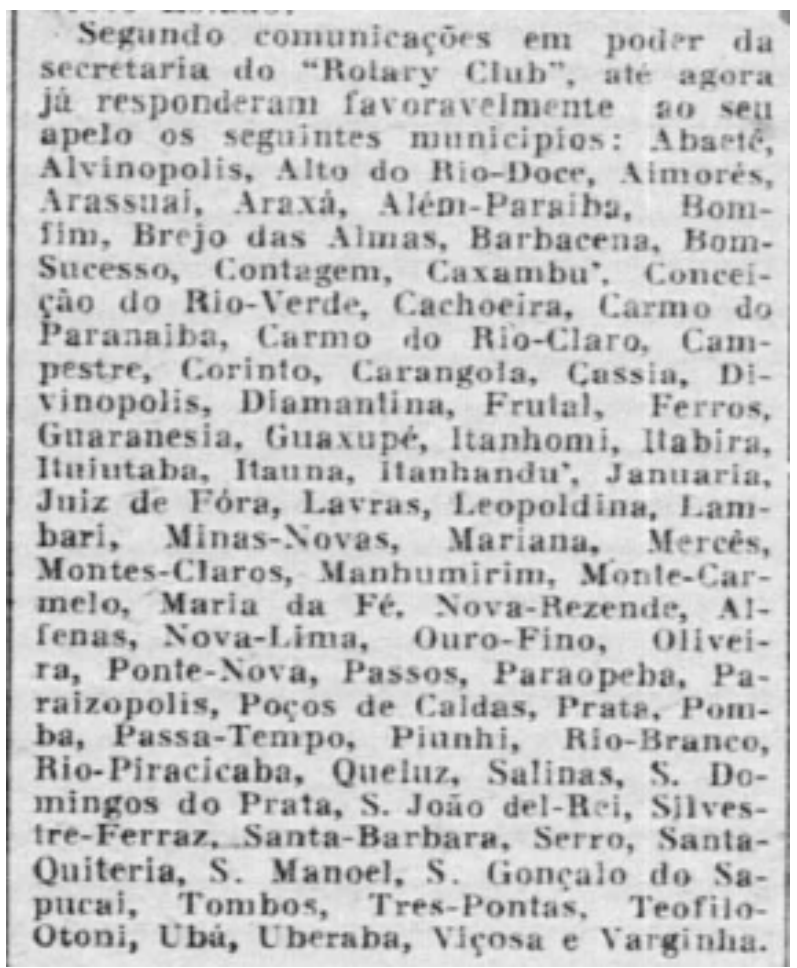

Fonte: Minas Gerais, 03 de dezembro, 1931. p.9.

O pedido de contribuição fora feito pelo Rotary Club, uma organização formada por líderes de negócios e profissionais, que se define por prestar serviços humanitários. Desse modo, a organização, que gozava de prestígio na sociedade, apelava para que as prefeituras firmassem o compromisso de contribuir com a "Sociedade Mineira..." na tarefa de "cuidar" dos leprosos isolados. A divulgação dos municípios que se dispuseram a contribuir pode ser considerada como uma estratégia interessante, pois, ao mesmo tempo em que destacava a "solidariedade" dos mesmos, também excluía aqueles que não haviam atendido ao pedido do Rotary Club.

A publicação de listas não se dava apenas em relação aos municípios, mas também às pessoas que se tornavam sócias da entidade de "proteção aos lázaros". Na edição do Minas Gerais, de 04 de dezembro, por exemplo, fora divulgada uma lista de novos "beneméritos" da "Sociedade Mineira... de Belo Horizonte". Entre os nomes, estavam diversos médicos daquela cidade. Igualmente recorrente nas páginas do jornal, era a criação de novas filiais da entidade. Ao longo do mês de dezembro de 1931, foram criadas sucursais da entidade em Nova Lima, Formiga e Itajubá.

Como destacamos anteriormente, dezembro foi um mês em que os anúncios da "Sociedades de Proteção aos Lázaros e Defesas contra a Lepra" se 
avolumavam e, embora nos estudos sobre esta entidade seja evidenciado que as suas iniciativas consistiam no cuidado com os filhos indenes dos doentes, em Minas Gerais, percebemos que as campanhas, divulgadas no jornal, não eram direcionadas exclusivamente para os preventórios. Em 19 de dezembro, já próximo ao natal, bem como da inauguração do maior leprosário do estado - e um dos maiores do país -, fora publicada a nota que preferimos reproduzir na íntegra, a fim de observamos melhor o caráter de apelo à solidariedade do povo mineiro.

Figura 6: Jornal Estado de Minas

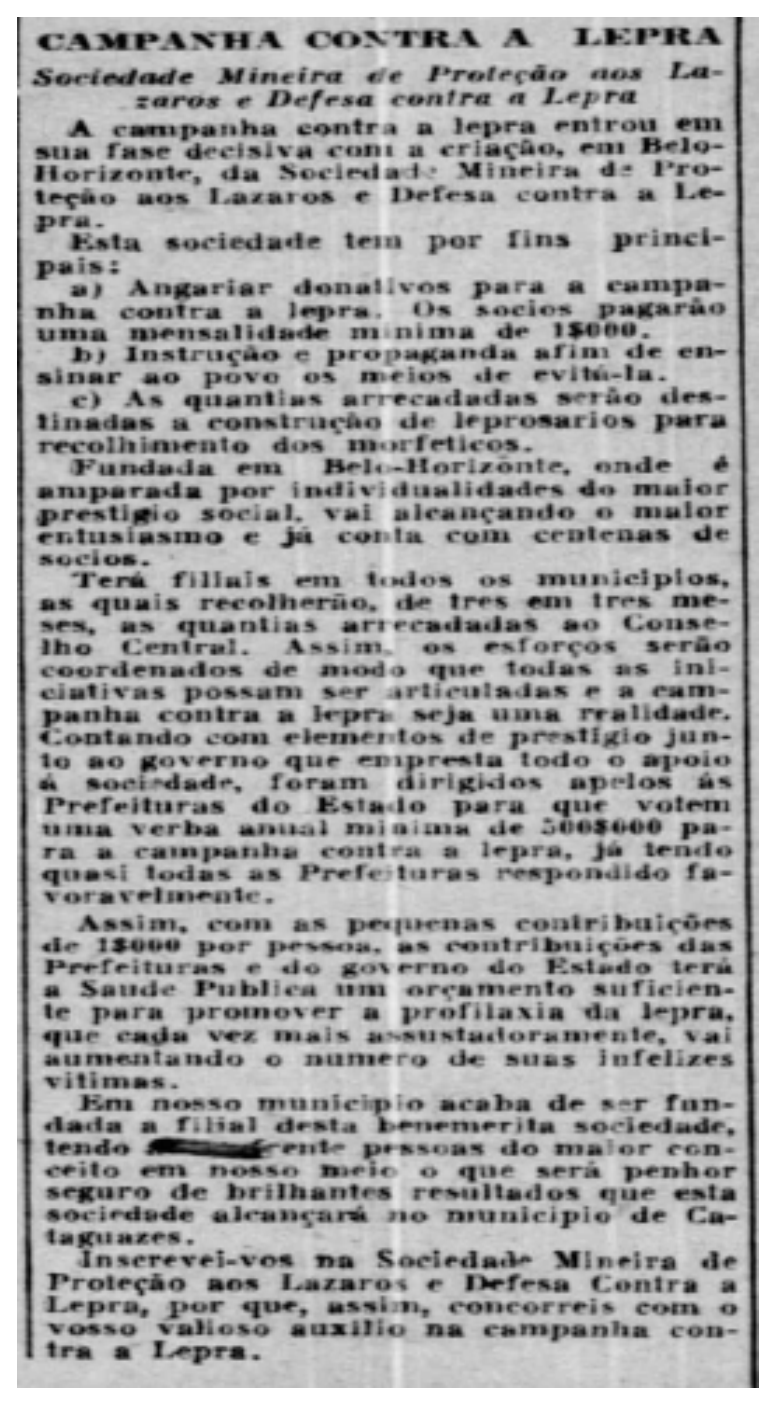

Fonte: Minas Gerais, 19 de dezembro, 1931. p.6.

Apesar de a filial da entidade existir em Belo Horizonte há algum tempo, aproveitando-se do período natalino, apelava-se para que houvesse novas adesões. Os sócios pagariam uma mensalidade no valor mínimo de 1 mil réis (mo- 
eda do período [8]). Além disso, as ações, a serem efetivadas com os donativos, objetivavam contribuir com o poder público na tarefa de promover a profilaxia da lepra, doença que avançava em números de casos no estado. Notemos que se enfatiza, na nota, o fato de a sociedade já ser "amparada por individualidades do maior prestígio social", ou seja, além de exercer a solidariedade, ao se juntar a entidade, poder-se-ia desfrutar da parceria com membros da alta sociedade belo-horizontina.

Os beneméritos da "Sociedade Mineira de Proteção aos Lázaros e Defesas contra a Lepra”, ao contribuírem nas campanhas, eram agradecidos publicamente, através de notas na imprensa. Foi o que ocorreu, por exemplo, na campanha "Natal dos Lázaros de Sabará",

\begin{abstract}
Graças a generosidade do coração mineiro, os doentes daquele hospital puderam ter, este ano, um natal ameno [...]

Merece referencia especial a valiosa cooperação da Associação Comercial da União dos Varegistas de Belo Horizonte, que se apressaram em corresponder ao apelo da Sociedade de Proteção aos Lázaros, concorrendo com donativos para a realização da humanitária festa.

Merece, ainda, ser apontado o gesto de bondade de pessoas da nossa sociedade, que ofertaram ao hospital, várias coleções de discos para vitrola: Exmas. Senhoras d. Margarida Libanio, d. Berenice Martins Prates, dr. Otto Cirne, dr. IsamelLibanio, Helio Resende Alvim. (MINAS GERAIS, 1931, p.6.)
\end{abstract}

Os agradecimentos públicos eram uma espécie marketing, pois estimulavam a continuidade das doações, tanto quanto a captura de novos sócios para a entidade. Embora não fosse este o discurso presente de forma clara nas ações da “Sociedade de Proteção aos Lázaros”, envolver-se na profilaxia da lepra significava proteger os "sadios" da temível relação com o leproso. A retórica da solidariedade era reflexo de argumentos criados para legitimar uma política de saúde pública que arbitrava sobre a vida do indivíduo, determinando que o mesmo fosse excluído da sociedade e impedido de conviver, inclusive, com a própria família.

\title{
Conclusão
}

O isolamento compulsório foi uma prática profilática, determinada pelo significado que foi atribuído à lepra nas primeiras décadas do século XX, 
pois, neste contexto, a enfermidade se tornarauma questão médica. Os leprosos, que outrora eram assistidos pelas instituições de caridade, particularmente, pela Igreja e suas ordens religiosas, passaram a ser alvos da medicalização, tornandose assunto de saúde pública. Assim, no decorrer do processo pelo qual a lepra deixava de ser problema delegado à caridade cristã e se transformava em uma questão de política pública, a imprensa desempenhou um papel importante na difusão de um novo significado para a doença. Podemos observar que, se por um lado, os médicos leprólogos se empenharam em alterar o significado da doença, que a associava às noções de pecado, miséria e corrupção, dado que essas características estavam ligadas a uma perspectiva religiosa de compreendê-la; por outro lado, os novos significados seculares, que foram atribuídos a enfermidade, não se mostraram capazes de atenuar o estigma que historicamente estava associado a ela. Ao contrário, a ideia da lepra flagelo acabou corroborando para a construção de uma percepção mais temível ainda sobre a doença.

Mais temível, porque enquanto fenômeno biossocial, a enfermidade passou por um processo de medicalização, fato que a colocou entre as moléstias mais perigosas da humanidade, cujo perigo não se restringia à infecção do corpo humano e à ausência de cura, uma vez quese estendia para a civilização. Esse processo de medicalização, entretanto, não promoveu grandes avanços na compreensão da lepra, que permaneceu como uma doença misteriosa e incurável. Desse modo, o isolamento compulsório dos leprosos se mostrou como uma alternativa para evitar a disseminação da doença que se mostrava cada vez mais avassaladora. Política elaborada pelos agentes da saúde pública, institucionalizada pelo Estado e legitimada pela sociedade, o isolamento se tornou o grande instrumento de combate à enfermidade no Brasil, entre os anos de 1920 e 1960.

\section{Notas}

[1] O Decreto $\mathrm{n}^{0} 13.538$, de 9 de abril de 1919 , reorganiza o serviço de profilaxia rural. Brasil, Coleção das Leis da República dos Estados Unidos do Brasil, v.2, p.393-7, 1920.

[2] O Decreto $\mathrm{n}^{0} 3.987$ de 02 de janeiro de 1920, reorganizou os serviços sanitários federais e criou o Departamento Nacional de Saúde Pública (DNSP), órgão que proporcionou uma maior intervenção e centralização das questões de saúde dos estados. Na historiografia sobre história da saúde pública é recorrente a ideia de que o Departamento Nacional de Saúde Pública inaugurou uma nova etapa nas políticas de saúde pública e 
saneamento no Brasil. Nesta nova fase, o Estado assumiu maiores responsabilidades no que se referia à saúde da população, justamente porque o DNSP institucionalizou definitivamente as práticas sanitárias no interior do Estado da Primeira República. E o movimento que, anteriormente, se voltava para a problemática do mundo rural se ampliou e alcançou também os problemas de saúde pública presentes nas cidades. E a criação da Inspetoria de Profilaxia da Lepra e Doenças Venéreas foi uma das ações implementadas neste sentido. Sobre o DNSP, cf.: Hochman,1998.

[3] Cabe ressaltar que o modelo tripé fora proposto, inicialmente, pelo médico Aguiar Pupo após assumir a direção da Inspetoria de Profilaxia da Lepra do estado de São Paulo, em 1927.

[4] A filantropia era uma grande parceira do Estado na efetivação da política de controle da doença. Apesar de toda esta disposição em tomar parte na "cruzada" de combate à lepra, o aumento significativo do número de internações nos leprosários fez com que a "Federação das Sociedades de Assistência aos Lázaros e Defesa Contra a Lepra (FSAL e DCL)" não conseguissem dar conta, sozinha, de assistir aos filhos indenes dos leprosos e, por isto, requeresse ajuda do poder público, no sentido de ampliar os investimentos, estendendo-os, também, aos preventórios.

[5] Benedito Valadares foi nomeado governador de Minas Gerais, em substituição a Olegário Maciel, em novembro de 1933. O referido político, em 1935, fora eleito pela Assembleia Legislativa mineira governador de Minas Gerais. Com a instauração do Estado Novo, em novembro de 1937, foram nomeados interventores para os estados, sendo um deles Benedito Valadares. Portanto, permaneceu no cargo de governador, a partir de então, como interventor.

[6] A primeira instituição do gênero surgiu em São Paulo, "Sociedade de Assistência às Crianças Lázaras", criada sob a iniciativa da "dama da sociedade" Alice de Toledo Ribas Tibiriçá, no ano de 1926. Cf.: Miranda, 2005.

[7] Inicialmente, havia uma coluna no jornal Correio Paulistano, mas, devido a desentendimentos entre a presidente da entidade, Alice Tibiriçá, com o governo do estado, a coluna foi extinta. Cf.: Miranda, 2005.

[8] No ano de 1931, a média anual dos valores de equivalência das moedas: Dólar Americano para Mil Réis era de 0,07. Portanto, US $\$ 1$ equivalia a aproximadamente14\$286 (HOLLOWAY, 1984, p.268)

\section{Referências}

Conclusões da Segunda Conferência Panamericana de Lepra. In: Arquivos Mineiros de Leprologia, ano VI, n. IV, outubro, 1946.

COSTA, Dilma Fátima A. C. Entre Idéias e Ações: lepra, medicina e políticas públicas de saúde no Brasil (1894-1934). Tese de Doutorado, Universidade Federal Fluminense, 2007.

CURI, Luciano Marcos. "Defender os sãos e consolar os lázaros”: lepra e isolamento no Brasil 1935-1976. Dissertação de Mestrado em História, Universidade 
Federal de Uberlândia, 2002.

DINIZ, Orestes \& MARIANO, José. Assistência social aos filhos sadios dos doentes de lepra. Trabalho apresentado na $2^{\mathrm{a}}$ Conferência de Assistência Social dos Lázaros, Rio de Janeiro, 1945. In: Arquivos Mineiros de Leprologia, ano V, n. III, julho de 1945 .

DINIZ, Orestes. Nós Também Somos Gente: trinta anos entre leprosos. Rio de Janeiro: Livraria São José, 1961.

HOCHMAN, Gilberto. A Era do Saneamento. São Paulo: Editora Hucitec, 1998.

HOLLOWAY, T.H. Imigrantes para o café. Rio de Janeiro, Paz e Terra, 1984.

Jornal ESTADO DE MINAS, janeiro, 1931. Arquivo: Hemeroteca Histórica de Belo Horizonte.

Jornal ESTADO DE MINAS, dezembro, 1931. Arquivo: Hemeroteca Histórica de Belo Horizonte.

Jornal MINAS GERAIS, 1931. Arquivo: Hemeroteca Histórica de Belo Horizonte. Jornal MINAS GERAIS, 1937. Arquivo: Hemeroteca Histórica de Belo Horizonte. MACIEL, Laurinda Rosa. 'Em proveito dos sãos perde o lázaro a liberdade': uma história das políticas públicas de combate à lepra no Brasil (1941-1962). Tese de Doutorado em História, Universidade Federal Fluminense, Niterói, 2007.

MIRANDA, Maria Augusta Tibiriçá. Alice Tibiriçá: lutas e ideais. Rio de Janeiro: Ed. do Autor, 2005.

ORSINI, Olyntho. A Lepra no Brasil. Revista Médica de Minas, v. 3, n. 27, Belo horizonte, 1935 . 